\title{
EL PADRE ASESINADO EN COLOMBIA: ENTRE EL PADRE VIRIL Y EL PADRE AMOROSO
}

THE MURDERED FATHER IN COLOMBIA - BETWEeN THE MANLY AND THE LOVING FATHER

LE PÈre ASSASSINÉ EN COLOMBIE: ENTRE LE PÈre VIRIL ET LE PÈre AMOUREUX

\author{
Wilson Orozco \\ Doctor en Humanidades de la \\ Universitat Pompeu Fabra. Profesor \\ titular Traducción, Universidad de \\ Antioquia, Medellín, Colombia. \\ Calle 67 No. 53-108 Of. 12-127, \\ Medellín, Colombia \\ wilson.orozco@udea.edu.co
}

\begin{abstract}
RESUMEN
Este artículo analiza la figura del padre asesinado, que se enuncia en tres textos publicados en las últimas dos décadas en Colombia, escogidos por sus características testimoniales y literarias, por la posición central que en ellos tiene el asesinato del padre y por su importancia mediática. Así, en Mi confesión, de Mauricio Aranguren, No bay causa perdida, de Álvaro Uribe Vélez, y El olvido que seremos, de Héctor Abad Faciolince, la figura del padre se describe ampliamente, y su muerte se muestra como un trágico suceso que da lugar a una respuesta por parte del hijo. Se encuentra entonces que hay una relación entre las características de los padres descritos y las respuestas de los hijos frente al asesinato. De esta manera, tres tipos de reacción se pueden identificar: la venganza sanguinaria en Mi confesión, la lucha mesiánica para la salvación de la patria en No hay causa perdida, y el desencanto en El olvido que seremos.
\end{abstract}

Palabras clave: padre asesinado, relato testimonial, Mi confesión, Mauricio Aranguren, No hay causa perdida, Álvaro Uribe Vélez, El olvido que seremos, Héctor Abad Faciolince

\begin{abstract}
The present article analyzes the presence of the murdered father in three texts published over the last two decades in Colombia. The texts were chosen for their testimonial and literary characteristics, the centrality of the father's death to each of them, and the media impact of all three killings. In each text - Mauricio Aranguren's Mi confesión, Álvaro Uribe Velez's No hay causa perdida and Hector Abad Faciolince's El olvido que seremos - the image of the father is described in depth, and his death presented as a tragic event to which the son then responds. Similarities between the three fathers and the way their sons respond to their deaths are described. Three kinds of reaction are identified: bloody revenge in Mi confesión; saving the nation in No hay causa perdida, and disenchantment in El olvido que seremos.
\end{abstract}

Keywords: murdered father, confessional narration, Mi confesión, Mauricio Aranguren, No hay causa perdida, Álvaro Uribe Vélez, El olvido que seremos, Héctor Abad Faciolince

\section{RÉSUMÉ}

Cet article analyse la figure du père assassiné dans trois livres publiés au cours de vingt dernières années en Colombie, et qui en plaçant au centre de leur narration l'assassinat du père, revêt des caractéristiques de témoignage et littéraires. A cela 
s'ajoute l'importance médiatique qu 'ils ont suscitée. En effet, dans Mi confesión de Mauricio Aranguren, No hay causa perdida de Álvaro Uribe Vélez, tout comme dans El olvido que seremos de Héctor Abad Faciolince, la figure du père y est largement décrite et sa mort est représentée comme un évènement tragique qui appelle une réponse de la part du fils. Il s'établit alors une relation entre les caractéristiques des pères décrits et les réponses des fils face à leur assassinat. Trois types de réaction peuvent être identifiés: la vengeance sanglante dans $M i$ confesión, une lutte messianique pour sauver la patrie dans No hay causa perdida et l'écriture désenchantée dans El olvido que seremos.

Mots-clés : père assassiné, récit testimonial, Mi confesión, Mauricio Aranguren, No hay causa perdida, Álvaro Uribe Vélez, El olvido que seremos, Héctor Abad Faciolince 


\section{Introducción}

En las primeras décadas del siglo XXI se publicó en Colombia toda suerte de textos que intentaron dar versiones paralelas a la historiografía oficial colombiana en la forma de narración testimonial. Es el caso de Amando a Pablo, odiando a Escobar (Vallejo, 2008), que detalla secretos de la vida del narcotráfico; o La vida no es fácil, papi (Botero, 2011), que da otra perspectiva de la vida en la guerrilla, descripciones ambas ausentes en los medios de comunicación colombianos. Pero estos son solo dos ejemplos de la miríada de textos que se pueden encontrar en las ventas informales que pueblan las calles colombianas; ello, tal vez, por su carácter confesional y, por qué no, catártico, donde los lectores han podido encontrar otras versiones de la historia. En otras palabras, su evidente presencia en la forma de ediciones populares es sintomático de que son lecturas que atraen la atención del amplio público lector, dado que allí se pueden hallar otras verdades ausentes en los medios oficiales.

De ese amplio conjunto de textos resulta interesante el tratamiento que en tres de ellos se hace del asesinato del padre y la narración de la consecuente reacción de los hijos. Estos textos, además de bastante mediáticos, son: Mi confesión, escrito por el periodista Mauricio Aranguren y publicado por primera vez en 2001, convirtiéndose inmediatamente en uno de los más vendidos de ese año, hasta llegar incluso "en el 2002 a su duodécima edición” (Gonzálvez Torralbo, 2007). Cinco años después, en 2006, aparece El olvido que seremos, del escritor Héctor Abad Faciolince, quien a su vez tacha el anterior libro de "sucio" (Abad Faciolince, 2006, p. 267), ya que allí se relata precisamente, de manera cínica y cruda, la orden de asesinar a su padre. El último de los textos es No hay causa perdida, de reciente publicación (en 2012), y que se sitúa en el género de las memorias políticas, en concreto las del expresidente colombiano Álvaro Uribe Vélez.

\section{El género testimonial}

Partamos de hacer una diferenciación entre memoria e historia. Para Suárez (2016), una división esencial es que en la primera se puede identificar a una víctima que da cuenta de unos hechos trágicos, mientras que la segunda sería más bien una reconstrucción textual, una interpretación de tales hechos: diferencia no del todo clara ya que el término memoria también puede implicar una reconstrucción textual. En todo caso, citemos sus palabras: "La memoria produciría recuerdos y la historia conocimiento" (p. 18). Igualmente, recordar los hechos es importante, ya que "de ahí dependen nuestras convicciones, sentimientos e identidades —individuales y colectivas-. Este sería el primer paso de la memoria” (Suárez, 2016, p. 25).

Por otro lado, el género testimonial, vinculado más con la memoria, es bastante amplio, y por ello, si nos atenemos a clasificaciones architextuales - es decir, al fenómeno dela transtextualidad propuesto por Genette (1989) - , hallamos etiquetas como "literatura testimonial", "literatura documental" o simplemente "testimonio" (Gómez, 2003; Suárez, 2011 , p. 282). En todo caso, lo que sí caracteriza al género es el dolor (Gómez, 2003), sufrimiento derivado generalmente de un conflicto entre fuerzas opuestas, y donde una de ellas termina por ser la víctima que narra (Suárez, 2011, p. 279). La víctima querrá poner en palabras todo aquello que fue traumático, constituir en el entramado simbólico lo irrepresentable, con el fin de compartir, aleccionar o sanar.

Por otra parte, como lo testimonial está profundamente vinculado con aseverar y dar cuenta de hechos reales, el género cuenta casi siempre con un narrador en primera persona, letrado la mayoría de las veces, capaz de poner en palabras el dolor sufrido (Gómez, 2003; Ortiz, citado por Suárez, 2011, p. 290). Todo esto da como resultado la hibridez del género: entre la biografía y la autobiografía, entre la literatura y la antropología (Gómez, 2003, p. 43). De tal manera que las fronteras son bastante 
permeables, albergando novela, crónica o simplemente un texto confesional, cuyo evidente carácter literario es innegable (Suárez, 2016, p.37). De hecho, Suárez presenta una suerte de definición del género, al afirmar que

Perfilada así la literatura testimonial o el testimonio en tanto tema, estilo y composición (libro publicado con la extensión de una novela en la que tiene centralidad un testigo que narra desde la oralidad lo sucedido en una vida a partir de elementos memoriales y políticos), puede hablarse de su cercanía o identidad con otras denominaciones del testimonio y con otros géneros discursivos (2016, p. 36).

En cualquier caso, dicho testimonio, bien sea que posea toques de ficción o no, servirá siempre a la construcción de una memoria colectiva. Y particularmente para nuestro contexto, Gómez afirma que el "testimonio colombiano actual es una autobiografía de lo público” (2003, p. 51).

El género, pues, goza ya de amplios estudios, que incluso lo han analizado desde el punto de vista formal, indicando sus características del todo reconocibles (Theodosiadis, 1996). Las trabajadas por Theodosiadis (1996), y más fácilmente reconocibles en nuestro corpus, tendrían que ver con su carácter colectivizante, la identificación biográfica, la intencionalidad, las marcas de oralidad, los personajes y la presencia de hechos sociohistóricos. Así, antes de pasar entonces al análisis del corpus, es conveniente indicar también que los sucesos de las obras se sitúan en los años ochenta, años que, para Suárez, marcan nuevas formas de violencia en Colombia, concretamente en relación con el paramilitarismo y el narcotráfico, y la posterior representación de dicha violencia en el género testimonial (2011, p. 287).

Por otro lado, el corpus elegido tuvo que ver con los inicios del siglo XXI en Colombia, y con la condición de que hubiera un padre asesinado, junto con la respuesta del hijo a dicha muerte. Esta, por supuesto, consecuencia del conflicto interno colombiano, en particular el vivido por la guerra entre facciones de extrema izquierda y de extrema derecha.
Una vez determinado el corpus, se procedió a la lectura de los textos, atendiendo en especial a dos aspectos: el modo en que el padre es descrito; y luego, el momento dramático de su muerte.

Se utilizó el método hermenéutico de análisis, dado que son obras del pasado reciente (véase Eagleton, 1998), así como el análisis textual propuesto por González Requena (2006), propuesta fuertemente vinculada con el sicoanálisis. Desde el punto de vista formal, se recurrió a la narratología (Bal, 1990; Stam, Burgoyne y Flitterman-Lewis, 1999).

\section{Características de la narración}

Es fundamental preguntarse, primero, ¿quién es el responsable de esas narraciones en torno al padre? Para ello hay que decir que las tres narraciones poseen sus matices. En Mi confesión, el periodista Mauricio Aranguren (2001) mezcla el relato de Carlos Castaño con detalles del contexto en el cual se dieron las entrevistas que este último concedió. El actuar del periodista es entre cómplice y admirativo con el "criminal de guerra", como se señala en el subtítulo del libro. Tratamientos del tipo: "Está medio daltónico, comandante" (Aranguren, 2001, p. 316) o "Castaño", hacen ver al periodista más como un amanuense que como un entrevistador.

En No hay causa perdida (Uribe Vélez, 2012), igualmente otro periodista, Brian Winter, aparece como entrevistador y, según palabras de Uribe Vélez, "apoyo fundamental para escribir [el] libro" (2012, p. 333), sin aclararse en qué consistió ese apoyo (aparte de realizar las entrevistas): si en la escritura del libro como tal o en su asesoría para cumplir con dicha tarea. En todo caso, la narración parece hecha por un escritor avezado, ya que la narración juega con el suspenso, las analepsis y las prolepsis, junto con otros elementos formales que lo acercan a un texto narrativo con una fluidez casi novelesca. También las entrevistas se dan en un ambiente distendido, ya que Uribe Vélez afirma que estas se efectuaban mientras disfrutaban de 
"galletas que acompañaban con un buen vaso de leche" (2012, p. 333).

En ese sentido, El olvido que seremos (Abad Faciolince, 2006) se diferencia de los anteriores libros en que es un texto cuya responsabilidad es del reconocido novelista Héctor Abad Faciolince. Asimismo, en que, mientras los entrevistados de Mi confesión y No hay causa perdida son políticos o actúan con motivaciones políticas para justificar su accionar militar, en la novela de Abad Faciolince el narrador tiene una actitud mucho más desencantada y pesimista frente a cualquier tipo de acción.

De igual modo, los tres textos se basan en hechos reales, y están narrados con técnicas como la prolepsis y la analepsis, tradicionalmente identificadas con la ficción, sobre todo en el caso de El olvido que seremos. Y si bien Mi confesión y No hay causa perdida son el producto de versiones orales, su escritura fue realizada por periodistas, y con ello se cumple, en los tres casos, con aquella premisa de que el género testimonial se caracteriza porque su narración es acometida generalmente por un narrador letrado (Gómez, 2003; Suárez, 2011).

\section{Representación del padre en Mi confesión y No hay causa perdida}

Las características de los padres de Mi confesión y de No hay causa perdida son bastante afines a la imagen del padre en una sociedad machista y patriarcal: viriles, trabajadores y distanciados emocionalmente de sus hijos. Estos padres continúan en la línea del patriarcado, en el despliegue de la fuerza, encarnando las mejores virtudes del dominio de la naturaleza.

Antonio Castaño - el padre de Mi confesión - es presentado como un hombre campesino y trabajador que encarna también las mejores virtudes familiares y religiosas:

Mi padre tenía el concepto de que entre más hijos engendrara más personas trabajarían para el bienestar de la familia [...]. Los hijos eran un instrumento, con la diferencia de que en casa se respiraba mucho amor y una profunda fe católica (Aranguren, 2001, p. 59; el resaltado es mío).

Su visión religiosa de la vida se refuerza con su posición conservadora en la política: en algún momento le dirá a su hijo Carlos Castaño que frente al caos del país, eso solo puede ser solucionado por "un godito joven" (Aranguren, 2001, p. 55), en referencia al expresidente conservador Andrés Pastrana Arango. Religión y conservadurismo político se unirán a su obsesión con el trabajo de la tierra y que tendrá que ver con sus anhelos de ascenso económico, en la ampliación y la diversificación constante de sus negocios:

El viejo [...] se fue con Fidel a comprar una tierra cerca de Segovia [...] donde el dinero se veía circular [...]. En dos años mi padre logró levantar más de 600 reses y su ganado era apetecido. Rápidamente duplicó el capital labrado con dificultad en cuarenta años de trabajo en Amalfi (Aranguren, 2001, p. 59).

En ese sentido, ve, en todos aquellos que no le siguen su ritmo de trabajo, a una banda de perezosos. La concepción que tiene de los guerrilleros es despachada con un simple "son unos sinvergüenzas que no trabajan” (Aranguren, 2001, p. 57). Su personalidad, además, encaja con el mejor estereotipo del hombre adusto y viril, a través de los adjetivos utilizados para su descripción, como un hombre "fuerte", "rozagante"; "serio y caballero pero muy temperamental” (Aranguren, 2001, p. 61). Una vez las Fuerzas Armadas Revolucionarias de Colombia (FARC) lo secuestran por motivos económicos, las virtudes de la virilidad también las despliega en ese duro trance, ya que en ningún momento parece demostrar miedo ni sumisión frente a sus captores: "Mi padre se comenzó a enfermar durante el cautiverio. Sufría de problemas de gastritis, pues había decidido no comer nada y no hablar con sus captores. Duró meses sin pronunciar una palabra" (Aranguren, 2001, p. 62).

La hombría y sobre todo los deseos de prosperidad económica de Antonio Castaño son transmitidos a sus hijos, primero al mayor, Fidel, y luego al 
menor, Carlos. Ambos quieren vengar la muerte del padre al ver, tal vez, que realmente con esta se trunca el ascenso económico que ya había emprendido toda la familia. El primogénito, Fidel, se convierte entonces en el padre de esa huérfana familia y luego, metafóricamente, de toda la colectividad criminal, al considerársele el padre de las autodefensas en Colombia (Aranguren, 2001, p. 13).

Pero, como si fuera una réplica del padre y a la vez una superación de este, el texto señala que, en sus fincas, Fidel Castaño vestía a la usanza campesina, enfatizando su frugalidad con un "mandaba a remendar los pantalones" (Aranguren, 2001, p. 163). Ello resulta paradójico si se considera que ese mismo campesino, cuando viajaba a Europa, vestía trajes de "Ermenegildo Zegna o italianos Beltrami” (Aranguren, 2001, p. 163). El hijo, pues, se convierte en padre, y en uno que supera a su propio padre campesino en la forma del nuevo rico.

Sobre No hay causa perdida hay que decir que continúa en esa misma línea del padre viril, serio y adusto, pero también un tanto más dicharachero. De Alberto Uribe Sierra se dice que "trabajaba sin descanso" (Uribe Vélez, 2012, p. 18), y que vivía rodeado de gente como él, es decir, "gente trabajadora y honesta” (2012, p. 18). El trabajo, sin embargo, no impedía que fuera "un hombre jovial y carismático, la personificación misma de la salud, la felicidad y el vigor” (2012, p. 18). Era, además, un "consumado jinete y aficionado a la tauromaquia, daba con destreza la estocada final — con la espada, no con el rejón - a un toro montado en su caballo. Nada ni nadie lograba perturbar su buen humor habitual" (2012, p. 18). Su carisma lo convertía en un "Don Juan" con "un gran encanto" y "fuente de alegría para quienes lo rodeaban" (2012, p. 18).

El asesinato de este padre se da prácticamente en las mismas circunstancias que las de Antonio Castaño: en una finca, y resistiendo el secuestro que querían realizar miembros de las FARC. De igual modo, se narra el enorme dolor que ello produce en el hijo, dolor que es expresado con violencia. Uribe Vélez, al enterarse de la muerte de su padre, afirma que

[...] mis ojos se llenaron de lágrimas y golpeé la cabrilla con desespero. Ahora yo era parte de la mitad de los colombianos que habían perdido a un ser querido debido a la violencia que azotaba al país (2012, p. 29).

La venganza sanguinaria aceptada cínicamente y sin recato por Carlos Castaño es, en contraste, negada por el narrador de No hay causa perdida, quien desea desvincularse de ella, según declara explícitamente:

\section{En ocasiones se me ha descrito como una especie de Bruce Wayne suramericano: un niño privilegiado que juró vengar la muerte de su padre asesinado por bandidos. Dispuesto a hacer pactos con el diablo y a tolerar todo tipo de abusos con el fin de llevar a cabo mi "misión" sin importar el precio, entré a la política y llegué a la presidencia — según quienes así piensan- para vengarme de las FARC y de todos los grupos de izquierda (Uribe Vélez, 2012, p. 31).}

Pero este narrador también parece llamado a la acción, a la honra bíblica del padre, a través de su conversión en salvador y héroe de la patria, al intentar detener un estado de cosas para él apocalíptico, ${ }^{1}$ aunque sin explicar nunca las causas que llevan a los "bandidos" a crear tal desorden, ya que, en cuanto a "las características personales de los conspiradores no tienen importancia. Lo importante son las características de la conspiración" (Palmer, 1983, p. 94). Su respuesta es, pues, la del mesianismo, la del compromiso político, la misión siempre presentada como causa justa. La muerte de ese padre al inicio del texto - también en Mi confesión - sirve como efecto retórico y detonante para justificar el consiguiente accionar político-militar.

1 "Dios concede la victoria a la constancia" (Uribe Vélez, 2012, p. 85), la frase de Simón Bolívar, y "El coraje es estimado con razón como el primero de los valores humanos... porque es el valor que garantiza todos los demás" (Uribe Vélez, 2012, p. 43), de Winston Churchill, son epígrafes utilizados en estas memorias y que refuerzan esa idea de líderes que se han venido a representar como padres fundadores y salvadores de naciones. 
Esa reacción mesiánica de salvación de la patria se presenta como una reacción obligada, dado que "el héroe tiene que ser provocado a la violencia, y no puede permanecer indiferente hacia sus víctimas" (Palmer, 1983, p. 42; el resaltado es mío). El propio Castaño dice, por ejemplo, "sólo sé que soy lo que soy porque la guerra vino a mi casa, no tocó la puerta y entró sin avisar. En ese instante no encontré otra opción que defenderme" (Aranguren, 2001, p. 323). La muerte de ese padre anuncia la posibilidad latente de más asesinatos en un contexto de caos y desorden social. Esa visión apocalíptica de ambos narradores es entendible, según explica Palmer:

La conspiración, por otro lado, es una absoluta necesidad, porque es ella la que pone en acción el argumento. Sin ella no habría razón para que el héroe actuara, porque la justificación de sus actos es siempre que él reacciona a una agresión previa: un mundo que de otra forma estaría ordenado (un mundo que es presentado como ordenado si no fuera por la conspiración) es alterado por el villano, y el héroe actúa para restaurar la normalidad (1983, p. 46).

Esa obligación a emprender la lucha, que en el fondo al parecer no deseaban, está enfatizada por un sacrificio manifiesto que los narradores deben hacer. Lo sacrificado, por supuesto, está en el orden de la familia, la diversión y los intereses personales:

No sé bailar ni cantar; no sé contar chistes; la última película que vi en una sala de cine fue El llanero solitario, cuando apenas era un niño; me he perdido un sinnúmero de cumpleaños, de fiestas familiares, de momentos importantes en la vida. No me quejo, sin embargo (Uribe Vélez, 2012, p. 33).

Todo ello se justifica si de restablecer el orden y la autoridad perdida se trata, ${ }^{2}$ de restaurar un mundo idílico ausente y que se poseía atrás, en un pasado bucólico perdido:

$2 \mathrm{Al}$ respecto cf. Legendre (1994), quien plantea que una caída de la figura y autoridad paternal trae consigo una desintegración de la sociedad.
[...] recuerdo haber anhelado, en el nivel más puro y primario, vivir en una Colombia donde los hombres armados no invadieran nunca nuestra finca, donde mi familia estuviera segura y donde nadie tuviera que encerrarse dentro de su casa, mirando aterrorizado por la rendija de la puerta (Uribe Vélez, 2012, p. 54).

\section{El olvido que seremos y su ambigüedad genérica}

En contraste con las características de los padres en los anteriores dos textos y las respuestas de los hijos frente a sus asesinatos, es momento de hablar de El olvido que seremos. Esta novela se ha presentado paratextualmente como el homenaje que el narrador le hace a su padre, Héctor Abad Gómez, asesinado por sicarios en 1987 en la ciudad de Medellín. La lucha por los derechos humanos de este último fue vista por los paramilitares como un apoyo tácito a la guerrilla a la que estaban combatiendo. Las reseñas más comunes son del tipo "su valor es ante todo testimonial” (Cubides, 2006). Asimismo, las dedicatorias a Carlos Gaviria y Alberto Aguirre "sobrevivientes", y que luego aparecen en la diégesis, refuerzan ese aire testimonial en el que siempre se ha insistido.

De este modo, no es casualidad que en 2012 el autor haya ganado el "Premio Literario de Derechos Humanos”, concedido por la Oficina en Washington para Asuntos Latinoamericanos y la Universidad de Duke, con base en que, según la noticia del momento y la justificación del premio, Abad Faciolince "narra las iniciativas de su padre, del mismo nombre, quien desarrolló programas de salud pública para los pobres en Medellín, como parte de su activismo por la justicia social en su comunidad" (EFE, 2012). No hay duda, pues, de que aquí tenemos una suerte de novela histórica, en la que unos eventos reales se narran de manera ficcional, característica propia de dicho tipo de novela (Silva, 2013).

En ese sentido testimonial, la novela se acerca a Mi confesión y No hay causa perdida. En todo caso, El olvido que seremos ha estado precedida también por toda una maquinaria de reescritura 
(cf.Lefevere, 1992), que no ha escatimado en presentar esta novela al público lector mediante prólogos, contraportadas, presentaciones y demás, como la historia real de un (buen) padre asesinado. $\mathrm{Y}$, ¿no es eso suficiente ya para enganchar al lector, como cuando una película está precedida por la clásica advertencia: "Basada en hechos reales"?

Pero vistas las cosas desde otro ángulo, ¿qué es $E l$ olvido que seremos? ¿Es también un texto ficcional, en la medida en que ha sido etiquetada como novela? Y si es así, ¿qué tanto de ficción hay? $\mathrm{O}$ ¿es la excusa para que un escritor presente su autobiografía a través del amor por su padre asesinado? Aunque, ¿no podría ser una combinación de todas las anteriores al modo posmoderno? Estas son preguntas difíciles de responder y motivo de otro trabajo, pero que señalan de por sí una patente ambigüedad genérica (texto biográfico, autobiográfico, ficcional, confesional, etc.), la misma que experimentan los dos personajes principales, el padre y el hijo.

Aun así, aceptando que el texto remite a hechos reales de la historia de Colombia, hay que decir, sin duda, que si no fuera un texto bien narrado, y Elolvido que seremos lo es, si no contara una historia que enganchara, si no tuviera una tensión hacia el final, tal vez sería un texto condenado, ese sí, al olvido. Este no es el caso, porque, de hecho, $E l$ olvido que seremos, gracias a la siempre útil participación de la traducción, ha logrado ser un texto cada vez más reconocido. Ello, a juzgar por su traducción al inglés, lo cual con seguridad le valió el premio, anteriormente mencionado, en Estados Unidos.

\section{Del abuelo viril al padre e hijo amorosos}

Una vez anunciada esa ambigüedad textual de $E l$ olvido que seremos (novela testimonial, testimonio novelesco), hay que decir que en esta novela se dan, asimismo, las oposiciones entre un padre viril y un padre amoroso, encarnados en los personajes de Antonio Abad, padre, y Héctor Abad Gómez, hijo. Se señala que entre ellos las cosas nunca fueron bien, que "había un trato distante, como si algo se hubiera roto en el pasado de ambos" (Abad Faciolince, 2006, p. 36). Tal trato distante, por supuesto, estará ausente en la relación entre Héctor Abad Gómez y Héctor Abad Faciolince.

Una de las distancias que establece Abad Gómez con su familia tiene que ver con el manejo del dinero, en una familia descrita como poseedora de un gran pragmatismo económico. Mientras toda ella está dedicada al lucro, Abad Gómez termina por ser reconocido como poseedor de inteligencia, sí, pero de una inteligencia que resulta ser diferente y por qué no decirlo, "inútil":

En la casa de mi abuelo se decía que había dos tipos de inteligencia, la inteligencia "de la buena", y "la otra”, que aunque no se dijera que era mala, el juicio quedaba implícito, pues mientras la inteligencia "de la buena" (la que tenían algunos de mis tíos y de mis primos) era la que servía para conseguir plata, "la otra" sólo servía para enredar las cosas y complicarse la vida (Abad Faciolince, 2006, p. 37).

Llama la atención aquí el entrecomillado de "la otra" inteligencia, ya que eso "otro" va a ser una de las características de Abad Gómez, siempre presentado como un extraño, un ave rara incomprendida en su medio. Esa rareza es transmitida con ahínco a su pequeño hijo Abad Faciolince, a quien anatema para el machismo, osando incluso en llamarlo mi amor. Ambos estarán unidos, pues, en la diferencia con respecto a las formas tradicionales de ser hombre.

El abuelo, Antonio Abad, ese representante del hombre tradicional, está constantemente señalando el peligro que tal educación pueda albergar para su nieto. Pontifica una y otra vez que no se está cumpliendo con la labor de volver un hombre a ese niño, que se lo malcriará de por vida y de quien sentencia: "A este niño le falta mano dura" (Abad Faciolince, 2006, p.35). La respuesta de José Abad Gómez conlleva un tono que hace que la novela parezca también, a veces, un apunte de reflexiones edificantes, cuando dice que "si le hace falta [mano dura], para eso está la vida, que acaba 
dándonos duro a todos; para sufrir, la vida es más que suficiente, y yo no le voy a ayudar" (Abad Faciolince, 2006, p. 35).

De manera que el padre sensible forma, a su vez, a un hijo sensible. Un hijo cuyo fundamento literario se halla en "los siete volúmenes de la Recherche" de Marcel Proust (Abad Faciolince, 2006, p. 193), mientras se encuentra con su papá en México, como si de dos enamorados que han escapado del yugo familiar se tratase. Y el abuelo, como si fuera realmente el superyó en este idilio, escribe una carta en la cual señala los peligros a los que se sigue exponiendo a su nieto:

A mediados de ese año el abuelito Antonio le escribió una carta a mi papá muy preocupado. Él se había enterado de que yo, en mi ideal de vida proustiano, me pasaba los días enteros tirado en una cama, o en un diván, leyendo novelas interminables y tomando sorbitos de vino de Sauternes, como si fuera una solterona retirada del mundo, un Oblomov de los trópicos, o un dandy maricón del siglo XIX (Abad Faciolince, 2006, p. 194).

Se hace interesante aquí la alusión a pasarse los dias tirado en un diván, porque es precisamente ese mismo narrador el que en algún momento asiste a terapia con una sicoanalista (sesiones pagadas por el padre) para tratar de entender su angustia homosexual. Para tratar de entender sus deseos homoeróticos hacia sus compañeros de estudio y que, parece, no son aceptados por él. Hacia el final, el narrador encuentra que la terapia le fue de utilidad, al descubrir en sí una real inclinación heterosexual. Tanto, que emprende una cacería de mujeres, incluso las del prójimo, en una feliz demostración de que ya no se siente "atormentado” (Abad Faciolince, 2006, p. 144).

Aunque la terapia le sirve para descubrir su pasión de macho por las mujeres, sigue siendo un hombre cobarde como su padre, en lo que respecta a cuestiones vulgares como enfrentarse a los ladrones. El padre, sin embargo, demuestra mucha más valentía (¿o temeridad?) ante las amenazas de muerte que recibe constantemente, cuando frente a las listas públicas de amenazados en las que aparece, no huye, y solo atina a decir que "se sentía muy honrado de estar en compañía de personas tan buenas y tan importantes y que hacían tantas cosas en beneficio del país" (Abad Faciolince, 2006, p. 232). Todo el mundo murmura que el próximo en caer será precisamente él, pero sigue adelante como Cristo, llevado a una muerte segura, en la escenificación de toda "una autoinmolación, en la ciudad que justo el año en que lo mataron, se estaba convirtiendo en la ciudad más violenta del mundo" (Cubides, 2006).

\section{Una novela buscando un pasado perdido}

El narrador lo confiesa: los meses de lectura de En busca del tiempo perdido "fueron algo que marcaría para siempre mi vida como persona" (Abad Faciolince, 2006, p. 194). Así que el texto de Proust se puede entender sin mucha dificultad como un intertexto más de la novela. La principal función del recuerdo es reconstruir al padre y hacerlo suyo a través del texto confesional e íntimo, porque "qué mejor que la confesión para restituir ese olvido, rehabilitar esa unidad perdida [con el padre]" (Escobar, 2011, p. 189).

Al rememorar al padre, el narrador busca en su memoria, escoge eventos, edita y manipula versiones, alaba o condena, y es el que todo lo controla con su voz narrativa, ya que parece un hecho natural que se ha terminado por aceptar que Héctor Abad fue el padre de un único hijo, del narrador que nos lo reconstruye textualmente.

Ese recuerdo del padre es idealizado y así este termina por ser tanto héroe del niño como salvador de la sociedad en la cual vive. Un salvador que, aunque no religioso explícitamente, sí posee ciertos toques crísticos que lo llevan a ser sacrificado precisamente por la horda a la que él intenta salvar. Y si bien el padre vive rodeado de una extrema religiosidad que suena a mero ritual, va mucho más allá, al vivir la caridad en carne propia — como Cristo-, al entregarse a los más pobres y desprotegidos. 
También, como Cristo, sabe cuál es su destino y sigue adelante, a pesar de las amenazas de la horda inculta, es decir, va con plena conciencia hacia la inmolación, hacia la muerte por sus semejantes, y así el libro termina por ser el retrato de un "buen hijo de un papá aún mejor [...] el libro es un homenaje merecido a un padre que además era una excelente persona y lo mataron infames personas, y en forma inicua" (Cubides, 2006). Porque si hay dos palabras que describen a ese padre son la "benevolencia" y la "inocencia", esta última atribuida a los corderos, los mismos animales que tienen como función simbólica la expiación de los pecados (cf. Chevalier, 1986). ${ }^{3}$

Abad Gómez, en esa reencarnación de Cristo, propone un nuevo kerigma en las formas de la educación, la salud y la higiene. Ese kerigma

[...] funciona básicamente captando la imaginación del no creyente y persuadiéndolo de que allí está la solución de todos sus problemas; si triunfa, el no creyente es alcanzado por la ola de entusiasmo que le da la nueva fe. Los actos del héroe tienen un efecto similar. Inspiran a los que están de su lado, influyen en el ánimo de los que titubean, y paralizan la oposición. Y también persuaden al lector de que el héroe es admirable (Palmer, 1983, p. 111).

Ese héroe, en términos generales, tiene la función de desterrar el mal y la injusticia, al modo de la novela de misterio, donde el mal aparece de manera inexplicable, pero a la vez justificando la existencia de dicho héroe para resolver el misterio, evitar el crimen, combatir el mal y restituir el orden. Un héroe, por demás y como sería el caso de Héctor Abad Gómez, emparentado con lo patológico y lo mórbido. Porque se sabe que la

3 El cordero representa un "símbolo de dulzura, simplicidad, inocencia, pureza, obediencia, tanto en razón de su aspecto y su comportamiento naturales como de su color blanco, el cordero en todos los tiempos se ha considerado el animal de sacrificio por excelencia. Él fue la imagen de Cristo. La crucifixión, el viernes santo, evoca los sacrificios del cordero preparado para la pascua judía, así como el papel salvador de la sangre del cordero, con la que los judíos de Egipto habían marcado su puerta antes de la exterminación" (Chevalier, 1986, p. 344). gran pulsión de este es la salvación ilustrada por medio de la ciencia y, de modo más concreto, a través de las vacunas y la higiene:

Un rasgo que se presenta como una manía [en Abad Gómez es] la obsesión por la asepsia del epidemiólogo, las diversas campañas que adelantara [...] en pro del suministro de agua potable, de condiciones mínimas de higiene, la acción quijotesca que al cabo, en la medida en que va surtiendo efecto, deja una rentabilidad institucional, una ganancia neta (Cubides, 2006).

Porque si en la novela de misterio el detective es el que restaura el orden, y el crimen es visto como una irrupción exótica y amenazante, el médico es aquí quien tiene las intenciones de acabar con esos males endémicos que se ciernen sobre la población: primero la enfermedad biológica, luego la enfermedad de la violencia. Como si esa violencia lo invadiera todo al modo de un virus que hay que combatir con toda prontitud. En últimas, el padre es un héroe que se presenta como un héroe competitivo (ambicioso de la alabanza social), en un país sumido en males endémicos y que exigen ser combatidos.

Otra lucha que parece entablar el padre es contra la religiosidad reinante de su familia y que es trasladada al hijo. La ilustración del padre trastoca el ambiente católico que parece connatural e incuestionable. El nuevo mundo del arte, la ciencia, la literatura y la filosofía, introducido por el padre en la familia, es asumido y adoptado por el hijo con entusiasmo, pero no sin cierta crisis de identidad para este último (Escobar, 2011, p. 186).

\section{Asesinato del padre y ajuste de cuentas}

Habíamos dicho que, en la configuración heroica del padre, el narrador hace del todo una selección subjetiva del pasado. Es juez y parte, aunque en algún momento consulte otras voces, pero sin dejar de ser quien tiene la última palabra. Sobre todo en dos instancias, en lo que tiene que ver con la alabanza de los amigos de la familia y en la condena a la sociedad que, según él, llevó a su padre al sacrificio, gracias a la condena silenciosa 
y explícita que hizo sobre la figura incómoda del "médico comunista" (Abad Faciolince, 2006, p. 51). Como estos enemigos del padre no tienen voz (¿cómo podrían tenerla?), la novela se va convirtiendo en un agrio y solipsista ajuste de cuentas. El pueblo raso también, en su barbarie y sobre todo en su ingratitud, lleva parte de la responsabilidad, al no haber valorado en justa medida a su salvador. Esto resulta paradójico, ya que el narrador se reconoce a sí mismo igualmente como un "malagradecido" (Abad Faciolince, 2006, p. 39), proyectando de esta forma su falta de agradecimiento en la misma sociedad que él condena.

Así, se configura entonces el lugar común del héroe que es tratado injustamente a pesar de sus justas acciones, siendo incluso obligado al destierro y a la muerte. Por ello, no es coincidencia que la figura de Sócrates esté intertextualmente presente en la novela, sobre todo al rodearse de sus jóvenes discípulos, y que sea imposible soslayar su conexión con el padre, ese profesor universitario que proporcionaba a la vez conocimientos y recursos económicos:

Yo sabía que los estudiantes le pedían plata prestada porque muchas veces lo acompañaba a la Universidad y su oficina parecía un sitio de peregrinación. Los estudiantes hacían fila afuera; algunos, sí, para consultarle asuntos académicos o personales, pero la mayoría para pedirle plata prestada. Siempre que yo fui, varias veces mi papá sacaba la cartera y les entregaba a los estudiantes billetes que jamás le devolvían, y por eso alrededor de él había siempre un enjambre de pedigüeños.

—Pobres muchachos — decía-, ni siquiera tienen para el almuerzo; y con hambre es imposible estudiar (Abad Faciolince, 2006, pp. 16-17).

La metáfora de la labor y el destino de Sócrates no sirven solo para referirse al padre, sino también a dos de sus ilustrados amigos: Carlos Gaviria y Alberto Aguirre, personas que, según la narración, habían luchado para que Colombia, ese "país nuestro no sea completamente bárbaro" (Abad Faciolince, 2006, p. 270). Así los presenta el narrador:

Francamente yo no sé bien lo que quiere decir Sócrates en ["Lysis o de la amistad"]. Están hablando de la amistad, del bien y del mal, de alguien que no se tiñe las canas, sino que, al contrario, se tiñe de blanco el pelo, y parece canoso pero no es canoso. Cada vez que me pongo a leer los diálogos de Platón me enredo. Necesito un profesor canoso como este del que les estoy hablando [Carlos Gaviria], que ni se tiñe el pelo rubio de blanco, ni se tiñe de negro las canas, sino que es canoso desde joven. Canoso como es canoso el loco de Madrid [Alberto Aguirre] (Abad Faciolince, 2006, p. 270).

Paradójicamente, al parecer en una nueva muestra de ingratitud, es el país por el que han trabajado el que los obliga al exilio. El exilio de dos sabios, como el padre del narrador.

\section{Entre un presente apocalíptico y un pasado feliz}

Así El olvido que seremos se mueve en dos órdenes: rememora un pasado feliz e idílico, pero a la vez señala el caos reinante en el presente. Como si fuera la despedida de un mundo ya ido, gracias a los embates de lo nuevo que ingresa con toda su violencia.

En esa idealización del pasado, no son gratuitas entonces las diversas alusiones a escritores del Siglo de Oro, por ejemplo. El regreso al pasado también tiene que ver con la parodia del primer mandamiento, en el mismo inicio de la novela, como si asistiéramos a una especie de teogonía familiar: "En la casa vivían diez mujeres, un niño y un señor [...] El niño, yo, amaba al señor, su padre, sobre todas las cosas" (Abad Faciolince, 2006, p.11). En ese anuncio de amor incondicional se configura entonces una única presencia, donde solo tienen cabida padre e hijo. Esto, en desmedro de las mujeres, que resultan ser solo son un decorado en esa felicidad amorosa.

Por otro lado, las mujeres de El olvido que seremos no tienen una personalidad clara ni definida, ya que la narración poco se centra en ellas, a excepción de la esposa de Abad Gómez, que sí se presenta como un personaje fuerte y aguerrido, aunque emparentada realmente con las virtudes que se les conceden a los varones. Debe, por ejemplo, salir a completar 
el sueldo que al esposo no le alcanza, ya que ha sido desperdiciado, entre otras cosas, al regalarlo a los estudiantes que se acercan en romería a la oficina de su esposo. De hecho, es ella en realidad la autoridad familiar, la que se presenta como el obstáculo para que el niño no acceda (del todo) a su padre, la que se interpone para que no ocupe su lugar en la cama matrimonial:

Cuando me daba miedo, por la noche, me pasaba para su cama y siempre me abría un campo a su lado para que yo me acostara. Nunca dijo que no. Mi mamá protestaba, decía que me estaba malcriando, pero mi papá se corría hasta el borde del colchón y me dejaba quedar. Yo sentía por mi papá lo mismo que mis amigos decían que sentían por la mamá. Yo olía a mi papá, le ponía un brazo encima, me metía el dedo pulgar en la boca, y me dormía profundo hasta que el ruido de los cascos de los caballos y las campanadas del carro de la leche anunciaban el amanecer (Abad Faciolince, 2006, p. 13; los resaltados son míos).

Llama la atención, por supuesto, que el narrador solo se refiera a la cama de su padre, sin mencionar a la madre. Además, la presencia de los cascos de los caballos, las campanadas del carro de la leche, todo se configura para escenificar un amor del tipo cortés y cuyas características se pueden aplicar igualmente a la novela. El amor cortés incluye de por sí un origen cortesano de los amantes, la total sumisión de uno de ellos; el ser amado es siempre admirable y ambos pertenecen a la misma clase social (Simpson, 1998). Esa especie de amor cortés que el niño siente es, sin embargo, desmedido, y está teñido de instinto animal y connotaciones homoeróticas:

Yo amaba a mi papá con un amor animal. Me gustaba su olor, y también el recuerdo de su olor, sobre la cama, cuando se iba de viaje, y yo les rogaba a las muchachas y a mi mamá que no cambiaran las sábanas ni la funda de la almohada (Abad Faciolince, 2006, p. 13).

Esa declaración de amor se sitúa en el orden de la completa entrega: "El niño, yo, amaba al señor, su padre, sobre todas las cosas. Lo amaba más que a Dios" (Abad Faciolince, 2006, p. 11), resultando esto evidentemente en una parodia del credo católico. Así que, en adelante, padre e hijo se relacionarán estrechamente, la vida de ambos se mezclará, los dos jugarán a las máscaras, hasta no poder determinar, en últimas, quién es quién: el hijo sufre el mismo exilio que el padre, el hijo es confundido con él en la hora de su muerte, etc., porque, ya lo dice Escobar, en "esta autobiografíaconfesión el narrador se ve doblemente implicado" (2011, p. 189).

Aunque la parodia de ese credo católico no es la única alusión a la religión, en una novela plena de sustrato religioso: "Un día tuve que escoger entre Dios y mi papá, y escogí a mi papá” (Abad Faciolince, 2006, p. 11). Aquí ya se puede observar una apuesta por alejarse de la asfixiante religión, aunque solo intenta alejarse y toma partido por el padre ilustrado. Ese anuncio de no rezar más el credo, porque realmente se cree es en el padre, es más que contundente.

Ese reemplazo de Dios por el padre ilustrado está dado en un contexto laico y pequeñoburgués - la familia emplea, no hay que olvidarlo, a "dos muchachas del servicio" (Abad Faciolince, 2006, p. 11) - y el padre ilustrado se convierte ya - al menos para el hijo- en el modelo perfecto a seguir. Esa ilustración y sensibilidad lo convierten en alguien diferente del resto de padres e incluso se podría decir que del resto de los hombres. Aunque el padre seguirá siendo la cabeza de una familia que nadará siempre entre dos aguas: entre esa sensibilidad ilustrada y la connatural religión que parece imposible de abandonar y que el niño rechaza tímida, aunque culposamente, porque "el lastrado discurso religioso socava el supuesto discurso racional del narrador-hijo" (Escobar, 2011, p. 182). Sin duda, esa crisis, producto de la lucha entre ilustración y religión, resulta en una de las ambigüedades más fuertemente percibidas en la novela.

Religión y amor por el padre están, pues, íntimamente ligados, tanto que el narrador está incluso dispuesto a quitar cualquier obstáculo que se le interponga en la unión con ese padre, como cuando, por ejemplo, el narrador no intenta salvar 
a su hermana que está a punto de ahogarse. Con este evento en particular se entiende entonces cuando Sigmund Freud (s. f.) plantea que, en ocasiones, el niño lo único que lamenta es tener que compartir a sus padres con sus hermanos. Y todavía mucho más si esa visión que se tiene del padre es tan idealizada, que llega al punto de la deformación, de la irrealidad, convertido en alguien no humano, en Dios mismo. Según Freud, ese tipo de idealización propia del niño consiste en

Esa sustitución de ambos progenitores o del padre solo por unas personas más grandiosas, descubre que estos nuevos y más nobles padres están íntegramente dotados con rasgos que provienen de recuerdos reales de los padres inferiores verdaderos, de suerte que el niño en verdad no elimina al padre, sino que lo enaltece. $Y$ aun el íntegro afán de sustituir al padre verdadero por uno más noble no es sino expresión de la añoranza del niño por la edad dichosa y perdida en que su padre le parecía el hombre más noble y poderoso, y su madre, la mujer más bella y amorosa (Freud, 2007, p. 220).

Ese padre tan bueno - y tan irreal a la vez- le genera también una pesada carga al narrador. La famosa y simbólica muerte del padre se intenta dar, pero no se logra. Y se intenta dar cuando ya el niño ha pasado a ser un joven y viaja junto con su padre en carro por México. El narrador conduce, el padre duerme, e imposible no pensar en esa icónica escena de Thelma \& Louise (Scott, 1991), cuando el hijo busca deliberadamente acelerar el carro para morir junto con el padre, y así "sería una muerte instantánea de ambos en el desierto" (Abad Faciolince, 2006, p. 197). Esta escena cinematográfica es, pues, el "intento suicida y parricida; fugaz, y, claro, fallido. Pero es en aquellos pasajes en los que [el narrador] parece dispuesto a cometer el parricidio simbólico" (Cubides, 2006). Sin, por supuesto, lograrlo.

Al no darse esa muerte simbólica, se perpetúa ese carácter heroico del padre, tanto para el hijo como para la sociedad. Porque hay que recordar que es el padre quien lo ha rescatado de todas las mujeres que abundan en su casa y en su colegio. Pero no lo rescata solamente de las mujeres, también de ese catolicismo asfixiante que se respira en la familia.
El anhelo del hijo será siempre el ser salvado por el padre ilustrado, tanto de faldas como de sotanas.

Las formas de la salvación se escenifican sobre todo a través de la lectura, del encuentro con los libros y de las explicaciones extraídas de la enciclopedia Collier: es gracias a esta como el padre explica al niño cómo vienen los bebés al mundo, por ejemplo. La relación estará mediada siempre por el libro, y por su espacio natural, la biblioteca. Esta termina por ser el refugio del padre, sobre todo cuando está de mal humor, ya que allí se encierra con llave. Así que no sabemos mayor cosa de sus otras expresiones emocionales. Porque solo parece tener dos estados anímicos extremos: un permanente y enfatizado buen estado de ánimo o un mal humor prácticamente inexistente, que cuando se presenta resulta ser vergonzoso. Cuando la mala fortuna hace que aparezca ese mal ánimo, el padre se refugia en la biblioteca, para reprimir el dolor, la rabia o la frustración. Pero una vez se ha producido el paso por el espacio mitificado y fetichizado de la biblioteca, el padre sale renovado, con su mejor cara.

Así que en ese paso por la biblioteca, las referencias literarias allí aprendidas indican, una vez más, una vuelta al pasado y un anclaje a él. El Siglo de Oro español parece ser el favorito del narrador. Aparte de ello, cita a esos autores que han evocado el tema de la muerte con la "perfección del arte" (Abad Faciolince, 2006, p. 229), como san Juan de la Cruz, Cervantes, Quevedo y Jorge Manrique, en especial sus Coplas de don Jorge Manrique por la muerte de su padre. Este poema es de vital importancia, ya que el padre lo recita constantemente mientras padre e hijo caminan por el campo y, de tanto hacerlo, el hijo termina por aprender el poema de memoria. Uno de los versos de esas coplas da título precisamente a uno de los capítulos finales, "Cómo se viene la muerte", que anuncia tristemente el asesinato del padre.

Otros intertextos en la novela anuncian y señalan conexiones con la diégesis. El filme Muerte en Venecia (Visconti, 1971) remite tangencialmente 
a esa muerte en Medellín, pero, sobre todo, al amor ¿homoerótico, homosexual? del padre hacia ¿sus estudiantes? Porque no se dejan de percibir ciertos celos del narrador hacia esos estudiantes a los que trata precisamente de "pedigüeños”. En definitiva, esa película es clave para entender al padre (Cubides, 2006) y lo que el narrador cataloga como sus "zonas de sombra" (Abad Faciolince, 2006, p. 228).

Las referencias intertextuales tienen su cierre con el poema atribuido a Jorge Luis Borges que el padre llevaba en su saco el día de su muerte y uno de cuyos versos da título a la novela. Borges, junto con Proust, cerrarían ese ciclo de recuerdo, memoria, olvido y dolor con los que lucha constantemente el texto.

\section{Conclusiones}

Llama la atención que, en un lapso de apenas dos décadas, se hayan publicado en Colombia tres textos en torno a la figura del padre asesinado. Cada uno de ellos, por supuesto, tiene sus características peculiares, tanto por las causas del asesinato como por las respuestas de los hijos frente a su muerte: en Mi confesión y No hay causa perdida, por ejemplo, hallamos que, dada la desaparición de los padres más viriles y machistas, luego se manifiesta una evidente venganza en el caso del primero, y de una suerte de revanchismo en el segundo, a pesar de que este lo niegue. Como si las características de esos padres y la relación con sus hijos hubieran determinado dichas reacciones. En El olvido que seremos, por el contrario, el hijo del padre ilustrado solo opta por reconstruirlo a través de las palabras y no por la acción directa.

Por otra parte, en las tres narraciones, los padres aparecen siempre con características positivas: la vitalidad, en Mi Confesión y No hay causa perdida, o la sensibilidad, en El olvido que seremos. Estas características intentan lograr un efecto retórico, ya que entre más se enfatiza en estas virtudes, mayor también será el contraste que demuestra la injusticia de sus asesinatos. Así, la magnanimidad del patriarca - Antonio Castaño-, en Mi confesión, se opone a la ingratitud de los guerrilleros que lo asesinaron; el trabajo civilizatorio de Alberto Uribe Sierra, en No hay causa perdida, se opone al carácter monstruoso de los asesinos de las FARC; la sensibilidad de Héctor Abad Gómez se opone a la barbarie de sus asesinos y cómplices en $E l$ olvido que seremos.

El segundo elemento es que pareciera imposible no hablar del padre sin hablar del hijo. ${ }^{4} \mathrm{El}$ epígrafe de la novela de Abad Faciolince ya lo señala: "Y por amor a la memoria, llevo sobre mi cara la cara de mi padre" (Abad Faciolince, 2006, p.9) del poeta Yehuda Amijai. Escobar (2011) afirma igualmente, con respecto a esta novela, que "en su lectura primera parece una biografía del padre amado, [y] termina siendo - a pesar de la postura ideológica racionalista y agnóstica del narrador-hijo-autor- una confesión agónica y culposa cristiana" (p. 175). Esto de alguna manera se puede aplicar a los otros dos textos en cuestión. Porque, sin duda, la intención de los tres narradores es contar su historia, la historia de sus padres, pero a la vez justificar pragmáticamente sus acciones frente al lector.

Resulta también interesante observar la forma en que los hijos responden al asesinato de sus padres. En Mi confesión, Carlos Castaño —el hijo de un campesino, él mismo un campesino-ve la muerte del padre como la excusa para crear un ejército paramilitar (denominado con eufemismos de "autodefensa"), para combatir a la guerrilla a través de la masacre de la población civil, en una suerte de venganza sanguinaria. Álvaro Uribe Vélez — hijo de un ganadero; él también, entre otras, un ganadero- busca emprender una lucha mesiánica para salvar a la patria del caos a la que la tienen sometida sus enemigos los guerrilleros de las FARC, responsables asimismo de la muerte de su padre. Héctor Abad Faciolince

4 Liberman (1994) asimismo señala esto con respecto a la obra de Kafka, donde la unión entre padre e hijo es ineludible a la hora de hablar del uno o del otro. 
- hijo de médico y escritor, él también un escritor-, por el contrario, ve la desesperanza por doquier y su actitud es totalmente pesimista y nihilista frente a una Colombia que ve derrumbarse y sin posibilidades de salvación.

Por otra parte, la intención de contrastar a los padres de Mi confesión y No hay causa perdida con el de El olvido que seremos tenía por objetivo señalar que en poco más de una década aparecen padres totalmente opuestos, lo que convierte a esta última novela en un nuevo paradigma de la representación del padre en Colombia. Ese nuevo paradigma se funda en esa evidente demostración de amor y cariño hacia su hijo, por esas virtudes ya no centradas en la productividad y el trabajo, sino en la cultura, la ciencia y el arte. De hecho, el narrador expresa, en El olvido que seremos, que su interés al escribir la novela era la de dar una versión distinta - y opuesta - a la conocida Carta al padre del conocido autor checo: "Cuando, muchos años más tarde, leí la Carta al padre de Kafka, yo pensé que podría escribir esa misma carta, pero al revés, con puros antónimos y situaciones opuestas" (Abad Faciolince, 2006, p. 24).

Lo que sí queda claro es que si observamos de manera diacrónica la figura del padre en Colombia, podríamos llegar a pensar que El olvido que seremos representa un cambio en la tradicional figura patriarcal que bebe de la influencia judeocristiana. El padre machista, laborioso, duro y sin sentimientos se muestra aquí, en cambio, como progresista, sensible y cariñoso, aun demasiado cariñoso, según palabras del propio narrador. Un padre como nunca antes se había mostrado, incluso llegando a tocar un tema como una posible y ambigua descripción de su homosexualidad.

Los tres narradores quieren vengar la muerte del padre de alguna manera. Declarada o veladamente, por medios políticos o por medios (para)militares, por acción directa o indirecta: el narrador de El olvido que seremos guarda la camisa ensangrentada de su padre, por ejemplo:
[...] como una promesa de que tenía que vengar su muerte. Al escribir este libro la quemé también pues entendí que la única venganza, el único recuerdo, y también la única posibilidad de olvido y de perdón, consistía en contar lo que pasó, y nada más (Abad Faciolince, 2006, p. 225).

Perdido ese padre, la única forma que tiene el narrador de recuperarlo es a través del texto. El narrador hace suyo ese padre, porque él nos lo describe, se convierte en su único dueño y en el texto se funden en amor eterno. ${ }^{5} \mathrm{Y}$ en ese sentido, el narrador actúa como único guardián de la imagen de ese padre. ${ }^{6}$ Hay una insistencia en recuperar el objeto de amor mediante la escritura, pero a la vez de lanzar ese amor a la eternidad, porque bien se sabe que incluso el narrador está dispuesto a morir con el padre y así alcanzar juntos la inmortalidad (textual).

[Yo sabía que] lo iba a recordar siempre, y que lucharía por rescatarlo del olvido al menos por unos cuantos años más, que no sé cuánto duren, con el poder evocador de las palabras. Si las palabras transmiten en parte nuestras ideas, nuestros recuerdos y nuestros pensamientos - y no hemos encontrado hasta ahora

5 Al respecto, compárese con el último capítulo de Lolita de Vladimir Nabokov, donde Humbert, su narrador, busca fundirse en amor eterno con la adolescente, a través del texto que este escribe sobre ella: "Thus, neither of us is alive when the reader opens this book. But while the blood still throbs through my writing hand, you are still as much part of blessed matter as I am, and I can still talk to you from here to Alaska. [...] [O]ne wanted $\mathrm{H}$. H. to exist at least a couple of months longer, so as to have him make you live in the minds of later generations. I am thinking of aurochs and angels, the secret of durable pigments, prophetic sonnets, the refuge of art. And this is the only immortality you and I may share, my Lolita" (Nabokov, 2012, p. 308).

6 Con respecto a las formas en que se toma posesión del otro a través del acto de la narración, cf. Raguet-Bouvart (1996), quien analiza lo propio entre Humbert y Lolita: "d'une part une volonté absolue de possession, c'est lui le détenteur de l'information, et il ne livrera que ce qu'il veut bien laisser filtrer, et d'autre part le flou de son esprit, la focalisation sur certains points en certaines circonstances, que varieront en d'autres circonstances, et qui n'ont pour fonction que de révéler l'obsession constante et les phobies passagères de l'esprit de Humbert" (p. 26). 
un vehículo mejor para hacerlo, tanto que todavía hay quienes confunden lenguaje y pensamiento-, si las palabras trazan un mapa aproximado de nuestra mente, buena parte de mi memoria se ha trasladado a este libro (Abad Faciolince, 2006. p. 273).

Las palabras del narrador de El olvido que seremos bien pueden resumir el espíritu de los otros dos textos: la reconstrucción de un padre ausente, por medio de las palabras que rezuman amor y, a la vez, el dolor por su pérdida.

\section{Referencias}

Abad Faciolince, H. (2006). El olvido que seremos. Bogotá: Planeta.

Aranguren, M. (2001). Mi confesión. Carlos Castaño revela sus secretos. Bogotá: Editorial Oveja Negra.

Bal, M. (1990). Teoría de la narrativa: una introducción a la narratología. Madrid: Cátedra.

Botero, J. (2011). "La vida no es fácil, papi". Tanja Nijmeijer. La holandesa de las Farc. Bogotá: Ediciones B, Grupo Z.

Chevalier, J. (1986). Luna. En Diccionario de los simbolos (pp. 658-663). Barcelona: Editorial Herder.

Cubides, F. (2006). Reseña Elolvido queseremos. Recuperado de http://fcubides.tripod.com/sitebuildercontent/ sitebuilderfiles/abad-resenhacorrerevisa.pdf.

Eagleton, T. (1998). Una introducción a la teoría literaria. Buenos Aires: Fondo de Cultura Económica.

EFE (2012, 16 de octubre). Héctor Abad recibirá el "Premio LiterariodeDerechosHumanos”. ElEspectador. Recuperado de http://www.elespectador.com/noticias/ cultura/articulo-381405-hector-abad-recibira-elpremio-literario-de-derechos-humanos

Escobar, A. (2011). Lectura sociocrítica de El olvido que seremos: de la culpa moral a la culpa ética. Estudios de literatura colombiana, (29), 165-195.

Freud, S. (s. f.). Obras completas [versión pdf]. Recuperado de scribd.com.

Freud, S. (1999). La novela familiar de los neuróticos (1909 [1908]). En Sigmund Freud Obras completas, vol. 9 (pp.213-220). Traducción de José Luis Etcheverry. Buenos Aires: Amorrortu.
Genette, G. (1989). Palimpsestos: la literatura en segundo grado. Madrid: Taurus.

Gómez, B. (2003). Testimonio y género en el conflicto colombiano. Universitas Humanistica, 30(55), 41-61.

González Requena, J. (2006). Clásico, manierista, postclásico. Los modos del relato en el cine de Hollywood. Valladolid: Ediciones Castilla.

Gonzálvez Torralbo, H. (2007). Reseña de "Mi confesión. Revelaciones de un criminal de guerra” de Mauricio Aranguren Molina. AIBR. Revista de Antropología Iberoamericana, 2(1), 156-158. Recuperado de http://www.redalyc.org/articulo.oa?id=62320111.

Lefevere, A. (1992). Translation, Rewriting and The Manipulation of Literary Fame. Londres: Routledge.

Legendre, P. (1994). El crimen del cabo Lortie. Tratado sobre el padre. Madrid: Siglo Veintiuno de España Editores, S. A.

Liberman, A. (1994). La nostalgia del padre: un ensayo sobre el derrumbe de la certeza paterna. Madrid: Ediciones Temas de Hoy.

Nabokov, V. (2012). The Annotated Lolita. Londres: Penguin Modern Classics.

Palmer, J. (1983). La novela de misterio (thrillers): génesis y estructura de un género popular. México: Fondo de Cultura Económica. Recuperado de http://cataleg. upf.edu/record=b1072444 S11* spi.

Raguet-Bouvart, C. (1996). Lolita, un royaume au-delà des mers. Bordeaux: Presses Universitaires de Bordeaux.

Scott, R. (director) (1991). Thelma \& Louise [cinta cinematográfica]. Estados Unidos: Metro-Goldwyn-Mayer.

Silva, M. (2013). Avatares de la distinción histórica entre la escritura de la historia y la escritura de ficciones. Íkala, 18(2), 97-110.

Simpson, D. (1998). Chivalry and Courtly Love. Recuperado de http://condor.depaul.edu/dsimpson/tlove/ courtlylove.html

Stam, R., Burgoyne, R., y Flitterman-Lewis, S. (1999). Nuevos conceptos de la teoría del cine: estructuralismo, semiótica, narratología, psicoanálisis, intertextualidad. Barcelona: Paidós.

Suárez, J. (2011). La literatura testimonial de la guerras en Colombia: entre la memoria, la cultura, las violencias y la literatura. Universitas Humanistica, 72(72), 275-296. 
Suárez, J. (2016). La literatura testimonial como memoria de las guerras en Colombia. Medellín: Fondo Editorial FCSH (Facultad de Ciencias Sociales y Humanas) de la Universidad de Antioquia.

Theodosiadis, F. (1996). Literatura testimonial: análisis de un discurso periférico. Bogotá: Cooperativa Editorial Magisterio.
Uribe Vélez, A. (2012). No hay causa perdida. Londres: Celebra.

Vallejo, V. (2008). Amando a Pablo, odiando a Escobar. La increible historia de amor entre el narcotraficante más buscado del mundo y la estrella más famosa de Colombia. Barcelona: Debate.

Visconti, L. (director) (1971). Muerte en Venecia [cinta cinematográfica]. Italia: Metro-Goldwyn-Mayer.

How to reference this article: Orozco, W. (2018). El padre asesinado en Colombia: entre el padre viril y el padre amoroso. Íkala, Revista de Lenguaje y Cultura, 23(3), 433-449-xx. DOI: 10.17533/udea.ikala. v23n03a02 